\title{
MODELLING WAVE-INDUCED RESIDUAL PORE PRESSURE AND DEFORMATION OF SAND FOUNDATIONS UNDERNEATH CAISSON BREAKWATERS
}

\author{
Hisham El Safti ${ }^{1}$, Matthias Kudella ${ }^{2}$ and Hocine Oumeraci ${ }^{3}$
}

\begin{abstract}
A finite volume model is developed for modelling the behaviour of the seabed underneath monolithic breakwaters. The fully coupled and fully dynamic Biot's governing equations are solved in a segregated approach. Two simplifications to the governing equations are presented and tested: (i) the pore fluid acceleration is completely neglected (the $u-p$ approximation) and (ii) only the convective part is neglected. It is found that neglecting the pore fluid convection does not reduce the computational time for the presented model. Verification of the model results with the analytical solution of the quasi-static equations is presented. A multi-yield surface plasticity model is implemented in the model to simulate the foundation behaviour under cyclic loads. Preliminary validation of the model with large-scale physical model data is presented.
\end{abstract}

Keywords: caisson breakwater, sand foundation, porous flow, pore pressure, plasticity

\section{INTRODUCTION}

Caisson breakwaters are more advantageous compared to rubble mound breakwaters in terms of environmental considerations, quality control, construction speed and multi-purpose use (Oumeraci, 2004). However, most of the failures experienced by monolithic breakwaters are of geotechnical nature (Oumeraci, 1994). Despite the extensive research in the past (e.g. Oumeraci and Kortenhaus, 1994; Oumeraci et al. 2001; Kudella et al., 2006), the behaviour of sand foundations underneath monolithic structures, subject to breaking wave impacts, has not yet been satisfactorily numerically simulated (nor has it been fully understood). This is partially due to simplifications adopted in the governing equations (i.e. using uncoupled solution or Biot's quasi-static poro-elastic model (e.g. Liu and García 2006). For a comprehensive review of available models refer to Jeng (2003). Another significant aspect is the selection of a suitable soil constitutive model, which should be able to reproduce with acceptable accuracy salient processes such as the balance between pore pressure generation and dissipation and subsequent soil failure. Only few publications can be found with implementations of non-elastic models (e.g. Jeng and Ou 2010; Stickle et al., 2012). Nevertheless, the implementations do not consider the acceleration of the pore fluid which was proven necessary for the problem at hand (e.g. Ülker et al., 2012). A geotechnical model for the sand foundation is presented as a part of the development of a coupled CFD-CSD model system to reproduce numerically large-scale experiments from Kudella et al. (2006).

In this paper, a numerical model for the poro-mechanical behaviour of seabed is developed using the fully coupled formulation of Biot's governing equations as described in Zienkiewicz et al. (1999) and considers coupling between the solid skeleton and the pore fluid using a segregated approach. The model accounts for the dynamic behaviour of the solid skeleton and the pore fluid. It has been shown (e.g. Ülker et. al, 2012 ) that considering the pore fluid acceleration (dynamic effect) is relevant to soil foundations subject to high frequency cyclic loading (i.e. caisson motion due to breaking wave impact). The pore fluid acceleration is less significant for lower frequency cyclic loading (e.g. seismic action).

Two approximations are presented: (i) fully neglecting the pore pressure acceleration (i.e. the $u-p$ approximation), and (ii) neglecting only the convective part of the pore fluid acceleration. A comparison is made among the three solutions to investigate possibilities of simplifying the model by neglecting the convective part of the pore fluid acceleration.

\section{SEABED AS A POROUS MEDIUM}

Modelling the seabed as a porous medium is essential to realise the interaction between the skeleton and the pore fluid. Few approaches are available for describing the behaviour of porous media (all leading to the same results). Nevertheless, Biot's original formulation is the most widely applied in geotechnical engineering, especially by using the physical approach to the formulation provided in Zienkiewicz et al. (1999), which is used in this study.

\footnotetext{
${ }^{1}$ PhD student, Leichtweiß-Institute, TU Braunschweig, Beethovenstr. 51a, Braunschweig, 38106, Germany

${ }^{2}$ PhD student, Forschungzentrum Küste, Leibniz Universität Hannover, Merkurstraße, Hannover, D-30419, Germany

${ }^{3}$ Professor, Leichtweiß-Institute, TU Braunschweig, Beethovenstr. 51a, Braunschweig, 38106, Germany
} 


\section{Fully Dynamic Formulation}

An overall equilibrium equation (momentum balance) for the solid-fluid mixture, considering a control volume $(\mathrm{d} V=\mathrm{d} x . \mathrm{d} y . \mathrm{d} z)$, can be written as Zienkiewicz et al. (1999):

$$
\nabla \cdot \boldsymbol{\sigma}-\rho \frac{\partial^{2} \mathbf{u}}{\partial t^{2}}-\rho_{f}\left[\frac{\partial \mathbf{w}}{\partial t}+\underline{\mathbf{w} \cdot \nabla \mathbf{w}}\right]+\rho \mathbf{b}=0
$$

Where $\boldsymbol{\sigma}$ is the total stress tensor, $\mathbf{u}$ is the displacement vector and $\mathbf{w}$ is the average Darcy's velocity vector of the percolating fluid. The third term in the LHS of Eq. 1 represents the pore fluid acceleration relative to the solid phase. The underlined term represents convective pore fluid acceleration. Further, $\left(\rho_{f}\right)$ is the density of the fluid, $\mathbf{b}$ is the body force per unit mass tensor (mostly gravity) and $\rho$ is the density of the mixture defined as: $\rho=n \rho_{f}+(1-n) \rho_{S}$, where $\left(\rho_{s}\right)$ is the solid particles density and $(n)$ is the porosity. In Eq. 1 , the stress is defined in a generic incremental fashion that will permit later the implementation of constitutive model for any material as $\boldsymbol{\sigma}=\boldsymbol{\sigma}^{\prime}-p \mathbf{I}$ (tensile stresses are positive) and $d \boldsymbol{\sigma}^{\prime}=\mathbf{E}: d \boldsymbol{\varepsilon}^{\mathbf{e}}$, where $\boldsymbol{\sigma}^{\prime}$ is the effective stress tensor and $\mathbf{E}$ is the elasticity tensor and $\mathbf{I}$ is the identity tensor. The strain-displacement relationship is considered for the assumption of small-strain (further extension to large strain condition is feasible) as $\varepsilon=1 / 2\left(\nabla \mathbf{u}+(\nabla \mathbf{u})^{T}\right)$.

The momentum balance of the fluid phase alone considering the same control volume and assuming that the solid phase to be the reference is written as Zienkiewicz et al. (1999):

$$
\mathrm{w}-\nabla p-\mathbf{R}-\rho_{f} \frac{\partial^{2} \mathbf{u}}{\partial t^{2}}-\rho_{f}\left[\frac{\partial \mathbf{w}}{\partial t}+\underline{\mathbf{w} \cdot \nabla \mathbf{w}}\right] / n+\rho_{f} \mathbf{b}=0
$$

Where $p$ is the pore pressure and $\mathbf{R}$ is the viscous drag force vector (resistance). The viscous drag force can be defined according to the Darcy seepage law assuming an isotropic medium as $\mathbf{R}=\frac{\mathbf{w} \rho_{f} \boldsymbol{g}}{K}$, where $K$ is the hydraulic conductivity $(\mathrm{m} / \mathrm{s})$. Mass conservation of the fluid flow is achieved as Zienkiewicz et al. (1999):

$$
\nabla \cdot \mathbf{w}+\frac{\partial \varepsilon_{v}}{\partial t}+\frac{1}{Q} \frac{\partial p}{\partial t}=0
$$

where $\varepsilon_{v}=\operatorname{tr}(\boldsymbol{\varepsilon})$ is the volumetric strain of the solid skeleton, [1/Q $\left.=n / K_{\mathrm{f}}\right]$ and $\left[1 / K_{f}=S / K_{W}+(1-S) / p_{0}\right]$ where $K_{f}$ and $K_{w}$ are the bulk moduli for pore fluid and pure water respectively, $S$ is the degree of saturation $\left(S=V_{w} / V_{v}\right), V_{w}$ is volume of pore water, $V_{v}$ is volume of voids and $p_{0}$ is the absolute zero pore pressure (under atmospheric pressure $\approx 10^{5} \mathrm{~Pa}$ ).

\section{Approximations}

The governing Eq. 1-3 are always approximated for numerical solution to reduce the number of governing equations from three to two. This includes the $(u-p),(u-U)$ and $(u-p-U)$ formulations presented in Zienkiewicz and Shiomi (1984) and Zienkiewicz et al. (1999). These approximations prevent the solution of the pore fluid momentum balance. Instead, the momentum balance is presented implicitly in the pore fluid mass conservation. Therefore, the pore fluid pressure calculated always represents the "excess” pore pressure instead of the total pore pressure.

The $(u-p)$ approximation fully neglects the pore fluid acceleration with reference to the solid skeleton. The $(u-U)$ approximation includes the pore fluid acceleration but solves for two variables: the solid displacement vector $(\mathbf{u})$ and the total pore fluid displacement vector $(\mathbf{U})$. The $(u-p-U)$ approximation introduces the pore pressure to the equations as a dependant variable to enhance numerical stability.

In this model, the $(u-p)$ approximation is presented in a segregated approach to allow for comparison with the fully dynamic formulation. The $(u-p)$ approximation is realised by neglecting the pore fluid acceleration and substituting the pore fluid velocity divergence in the pore fluid mass conservation with the divergence of terms from the pore fluid momentum balance. The Eq. 1-3 reduce to Zienkiewicz et al. (1999): 


$$
\begin{gathered}
\nabla \cdot \boldsymbol{\sigma}-\rho \frac{\partial^{2} \mathbf{u}}{\partial t^{2}}+\rho \mathbf{b}=0 \\
\nabla \cdot\left(\frac{K}{\rho_{f} g}\left(-\nabla p-\rho_{f} \frac{\partial^{2} \mathbf{u}}{\partial t^{2}}+\rho_{f} \mathbf{b}\right)\right)+\frac{\partial \varepsilon_{v}}{\partial t}+\frac{1}{Q} \frac{\partial p}{\partial t}=0
\end{gathered}
$$

\section{THE "geotechFoam" SOLVER}

The OpenFOAM framework/toolbox is used to develop the geotechFoam solver. OpenFOAM is an open source collection of applications/libraries written in $\mathrm{C}++$ that provide infrastructure for developing numerical models (that can be inherently three-dimensional and run in parallel) as well as pre-/post processing utilities.

\section{Algorithm}

The geotechFoam solver uses a segregated algorithm for solving the coupled equations (Fig. 1) using the finite volume method. The segregated approach uncouples the equations at the iteration level. The governing equations are discretized into implicit terms, which are used for solution of current iteration, and explicit terms, which are updated from the previous iteration. The $(u-p)$ approximation is implemented in a straightforward manner. Nonetheless, the fully dynamic formulation and the dynamic formulation neglecting the pore fluid convective acceleration need an approach to resolve the velocitypressure $(w-p)$ coupling for the pore fluid. The same problem exists for CFD models. Therefore, the PISO algorithm (Pressure Implicit with Splitting of Operators) is adapted from incompressible NavierStokes solvers to solve the momentum balance and diffusion equations for the pore fluid (cf. Jasak, 1996).

\section{Discretization of Equations}

The governing Eq. 1-3 are decomposed into implicit and explicit parts in a fashion similar to that in Jasak and Weller $\left(2000^{\mathrm{a}}\right)$. The equilibrium equation is discretized as:

$$
\begin{aligned}
& \underbrace{\rho \frac{\partial^{2} \mathbf{u}}{\partial t^{2}}-\nabla \cdot((2 G+\lambda) \nabla \mathbf{u})}_{\text {Implicit }} \\
& +\underbrace{\rho_{f}\left[\frac{\partial \mathbf{w}}{\partial t}+\underline{\mathbf{w} \cdot \nabla \mathbf{w}}\right]-\nabla \cdot\left(\boldsymbol{\sigma}^{\prime}-(2 G+\lambda) \nabla \mathbf{u}-p \mathbf{I}\right)-\rho \mathbf{b}}_{\text {Explicit }}=0
\end{aligned}
$$

where $G$ is the shear modulus and $\lambda$ is Lame's constant. This infers that only isotropic linear elasticity is supported by the solver. Nevertheless, nonlinear elasticity is introduced by assigning different values for the elasticity parameters at each cell (normally as a function of confinement). Anisotropy is assumed to result from plasticity that is introduced explicitly to the stress term. In this manner, several material models can be incorporated with the solver.

In Eq. 6, the first term of the explicit part is completely neglected for the $u-p$ approximation. However, for the fully dynamic solution without pore fluid convection, only the underlined part $(\mathbf{w} \cdot \nabla \mathbf{w})$ is ignored.

Considering the $(u-p)$ approximation, the pore fluid mass conservation is discretized as:

$$
\underbrace{\frac{1}{Q} \frac{\partial p}{\partial t}-\nabla \cdot\left(\frac{K}{\rho_{f} g} \nabla p\right)}_{\text {Implicit }}+\underbrace{\frac{\partial(\nabla \mathbf{u})}{\partial t}+\nabla \cdot\left(\frac{K}{\rho_{f} g}\left(-\rho_{f} \frac{\partial^{2} \mathbf{u}}{\partial t^{2}}+\rho_{f} \mathbf{b}\right)\right)}_{\text {Explicit }}=0
$$




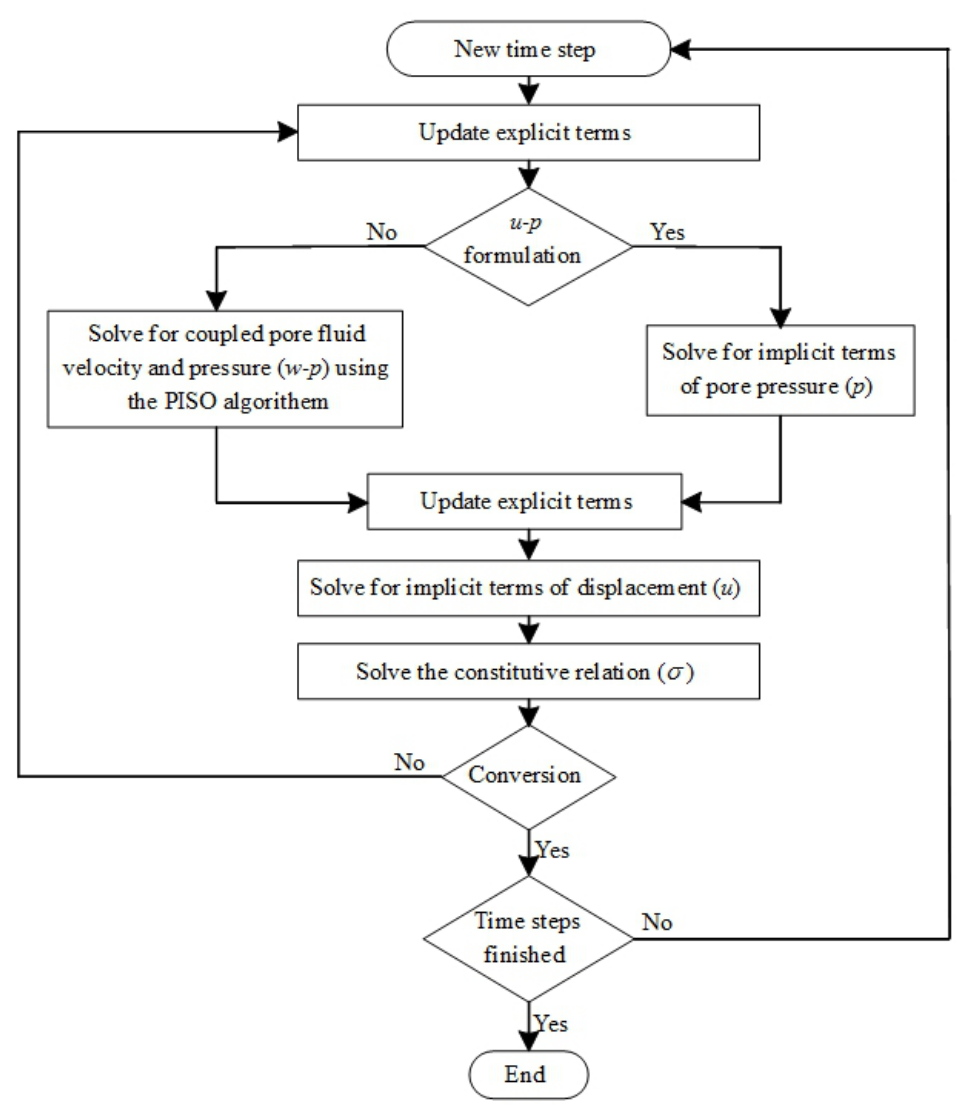

Figure 1. Algorithm for the geotechFoam solver

If the pore fluid acceleration relative to the skeleton $\left[\frac{\partial \mathbf{w}}{\partial t}+\underline{\mathbf{w} \cdot \nabla \mathbf{w}}\right]$ is considered, the pore fluid momentum balance is discretized as:

$$
\underbrace{\rho_{f}\left[\frac{\partial \mathbf{w}}{\partial t}+\underline{\mathbf{w} \cdot \nabla \mathbf{w}}\right] / n+\frac{\rho_{f} \boldsymbol{g}}{K} \mathbf{w}}_{\text {Implicit }}+\underbrace{\rho_{f} \frac{\partial^{2} \mathbf{u}}{\partial t^{2}}-\rho_{f} \mathbf{b}+\nabla p}_{\text {Explicit }}=0
$$

The underlined term is the convective acceleration that is neglected in one of the present formulations (the $u-p$ approximation). To calculate the pressure using the PISO algorithm, the momentum balance Eq. 2 is rewritten in a semi-discretized manner, pressure gradient is not discretized at this stage (Jasak, 1996):

$$
a_{P} \mathbf{w}^{\mathbf{P}}=\mathbf{H}^{\mathbf{w}}-\nabla p
$$

Eq. 9 is obtained from the integral form of the momentum Eq. 2. The parameters $a_{p}$ (the central coefficient) and $\mathbf{H}^{\mathrm{w}}$ (a vector including the transport part and source part of the momentum balance equation) are functions of the velocity $\mathbf{W}$. The velocity from (9) is:

$$
\mathbf{w}^{\mathbf{P}}=\frac{\mathbf{H}^{\mathbf{w}}}{a_{P}}-\frac{1}{a_{P}} \nabla p
$$

Substituting the velocity from Eq. 10 into the continuity Eq. 3: 


$$
\underbrace{\nabla \cdot\left(\left(\frac{1}{a_{P}}\right)^{f} \nabla p\right)-\frac{1}{Q} \frac{\partial p}{\partial t}}_{\text {Implicit }}-\underbrace{\frac{\partial(\nabla \mathbf{u})}{\partial t}-\nabla \cdot\left(\frac{\mathbf{H}^{\mathbf{w}}}{a_{P}}\right)^{f}}_{\text {Explicit }}=0
$$

The parameters $\left(\frac{1}{a_{P}}\right)^{f}$ and $\left(\frac{\mathbf{H}^{\mathbf{w}}}{a_{P}}\right)^{f}$ are face interpolates at cell faces. Eq. 11 is solved to get the total pore pressure. More information about the geotechFoam solver can be found in El Safti and Oumeraci (2012).

\section{MODEL VERIFICATION}

Two simple problems were simulated to verify the implementation of the equilibrium equation. A three dimensional bar fixed from one side and free from the other was tested under uniform uniaxial load at the free end with and without activation of gravity. The results are in agreement with hand calculations.

\section{One-Dimensional Poro-Elastic Problems}

To verify the solid-fluid coupling, the analytical solution of Terzaghi's one-dimensional consolidation of a soil layer is considered as shown in Verruijt (2001), which represents an uncoupled quasi-static solution. In this problem, the soil is initially considered undrained with an internal pore pressure equal to the external uniform surcharge (assuming incompressible pore fluid); afterwards the soil is allowed to drain upwards from the surface. The solution can be adjusted to describe the accumulation of pore pressure as a result of the sudden loading by a fluid on the soil surface (Detournay and Cheng, 1993). In the second problem the initial pore pressure is set to zero and the fluid pressure at the surface is set to an arbitrary value $\left(p_{i}\right)$. The configurations of both problems are illustrated in Table 1 , where $T$ is the external traction vector and $p_{i}$ is a predefined arbitrary pressure value.

Fig. 2 shows the results from different formulations as compared to Terzaghi's analytical solution. The results are shown for different dimensionless time $\left(\frac{c_{v} t}{h^{2}}\right)$, where the consolidation coefficient $\left(c_{v}=\frac{K}{\rho_{w} g\left(m_{v}+n / K_{f}\right)}\right)$ and the volumetric compressibility coefficient $\left(m_{v}=\frac{(1+v)(1-2 v)}{E(1-v)}\right)$. The consolidation coefficient $c_{v}$ is used to calculate the time values for sampling the results from the numerical simulations. The fluid bulk modulus in $c_{v}$ is considered for pure water (2200 $\mathrm{MPa}$ ) because Terzaghi's model assumes incompressible fluid. It is worth stressing that the degree of saturation $(S=$ $V_{w} / V_{v}$ ) has a great influence on the numerical model results (implicitly present in the fluid bulk modulus). An applicable value of $S=98.83 \%$ is considered, which best compares to the analytical solution and causes a reduction of $K_{f}$ by a factor $\approx 260$ from that of pure water $(S=100 \%$ ).

As shown in Fig. 2, the three formulations compare well to the 1D Terzaghi's consolidation model and the 1D loading by fluid case (adapted from the consolidation problem). It was observed that the fully dynamic Biot formulation (using the PISO algorithm) is affected by the ratio of the excess pore pressure to the hydrostatic pore pressure (more apparent for higher air content). The effect is significantly less apparent when the convective acceleration is neglected. At the beginning of the simulation, the change in pore pressure agrees relatively well with the analytical solution until the simulation reaches a certain time (dependent on ratio of excess to total pore pressure) then the pore pressure change is reduced significantly. Therefore, a higher value for the arbitrary pressure $p_{i}$ was considered for the PISO algorithm based simulations.

\section{Wave-Induced Seabed Response}

The effect of wave loading on an elastic seabed is studied using the three approaches (the fully dynamic solution, neglecting pore pressure convective acceleration and the $u-p$ approximation). The configuration of the problem is shown in Fig. 3. Properties of the wave loading are given in Table 3. The excess pore pressure ratio (pore pressure to wave pressure amplitude $q$ ) in the horizontal section (A-A) is shown in Fig. 4. In Fig. 5, the excess pore pressure ratio for the vertical section (B-B) is presented. 
As shown in Fig. 4 and 5, the three approaches give identical results for the pore pressure ratio. This means that direct seabed response is insensitive to dynamic effects of the pore fluid.

(a)

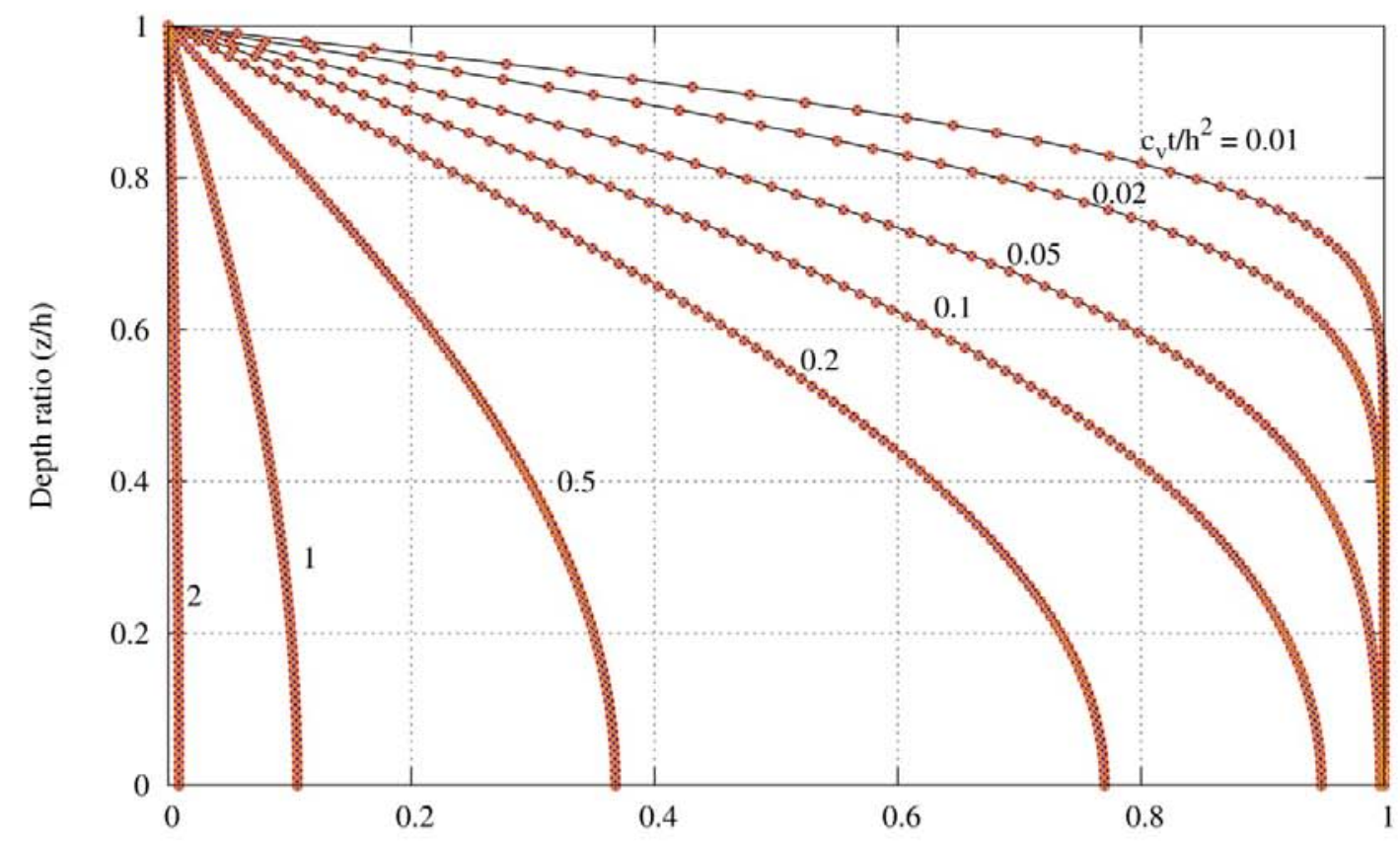

(b)

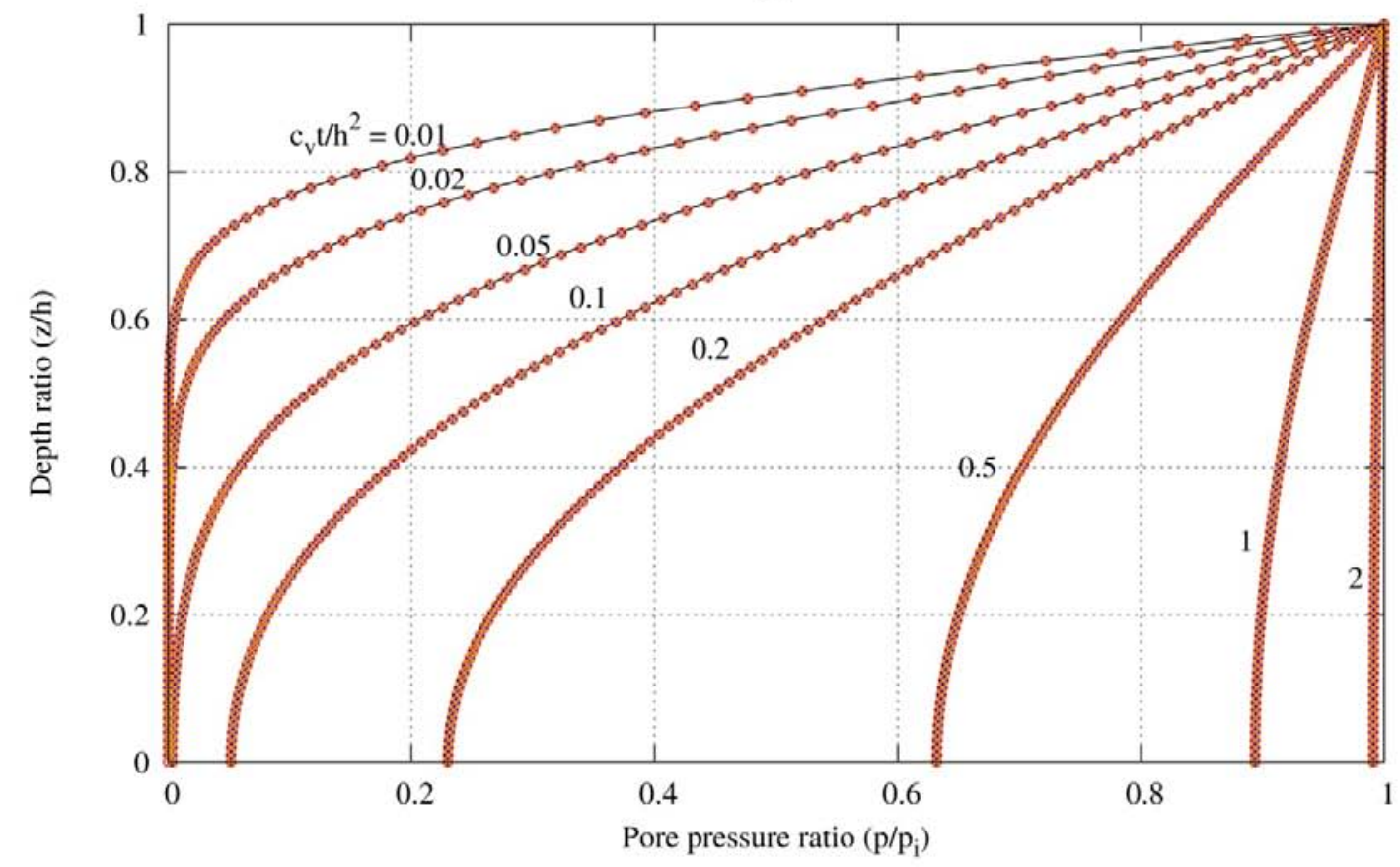

Terzaghi (analytical) u-p Approx. $\left(\mathrm{p}_{\mathrm{i}} / \rho_{\mathrm{w}} \mathrm{gh}=0.05\right)$ Fully Dynamic Biot $\left(\mathrm{p}_{\mathrm{i}} / \rho_{\mathrm{w}} \mathrm{gh}=56\right)$

Without conv. acc. $\left(\mathrm{p}_{\mathrm{i}} / \rho_{\mathrm{w}} \mathrm{gh}=4\right)$

Figure 2. Comparative analysis of the three approaches with Terzaghi's 1D consolidation model ( $\mathrm{S}=98.83 \%$ ): (a) Consolidation of a soil layer and (b) Loading by fluid 
Table 1. Configurations of the consolidation and loading by fluid 1-D problems

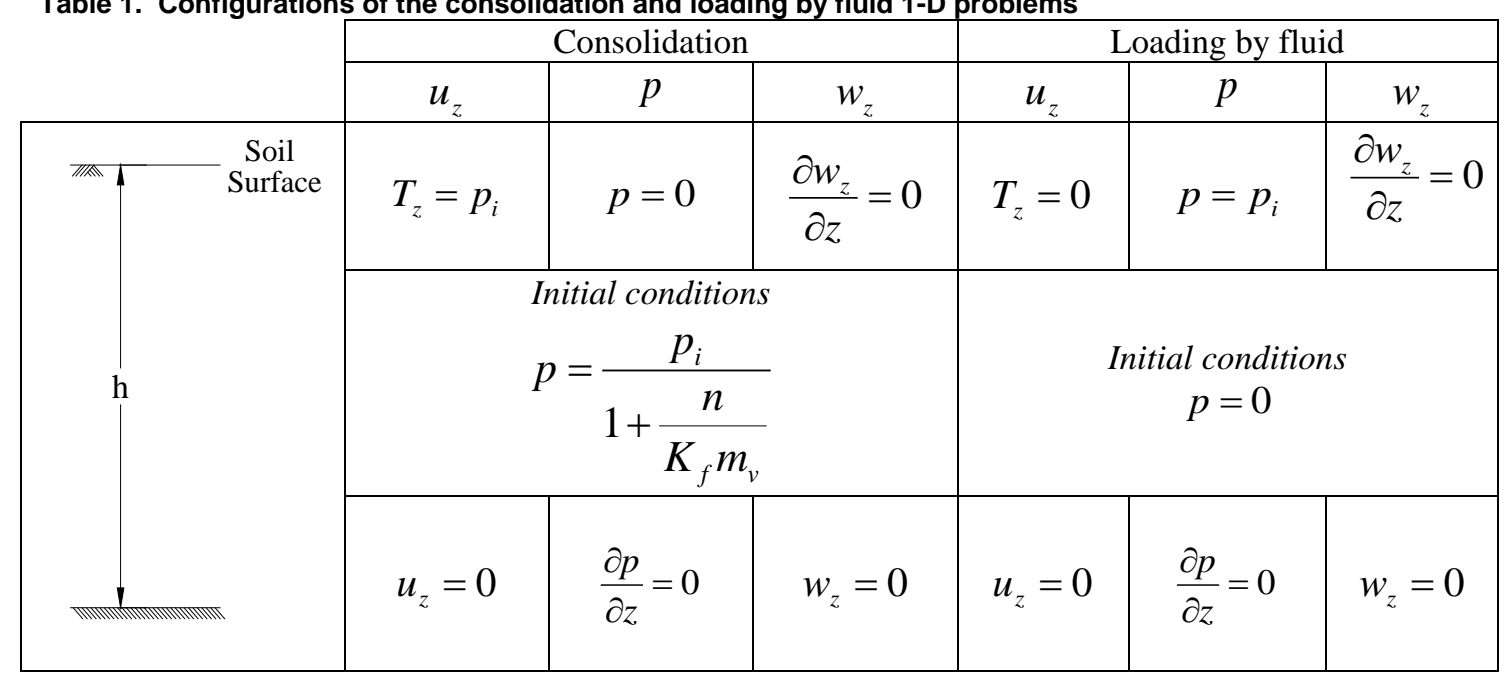

Soil properties used for the simulations are shown in Table 2.

Table 2. Soil properties

Layer thick. $(h)$

Arbitrary pressure $\left(p_{i}\right)$

Saturated density $\left(\rho_{\text {sat }}\right)$

Submerged density $\left(\rho_{\text {sub }}\right)$

Fluid density $\left(\rho_{f}\right)$

Porosity ( $n$ )

Hydraulic conductivity $(K)$

Elasticity modulus (E)

Poission's ratio $(v)$

Degree of saturation $\left(S_{w}\right)$

Fluid bulk modulus $\left(K_{f}\right)$
$10 \mathrm{~m}$

variable

$2000 \mathrm{~kg} / \mathrm{m}^{3}$

$1000 \mathrm{~kg} / \mathrm{m}^{3}$

$1000 \mathrm{~kg} / \mathrm{m}^{3}$

0.42

$10^{-5} \mathrm{~m} / \mathrm{s}$

$15 \mathrm{MPa}$

0.3

0.9883

8.514 $\mathrm{MPa}$

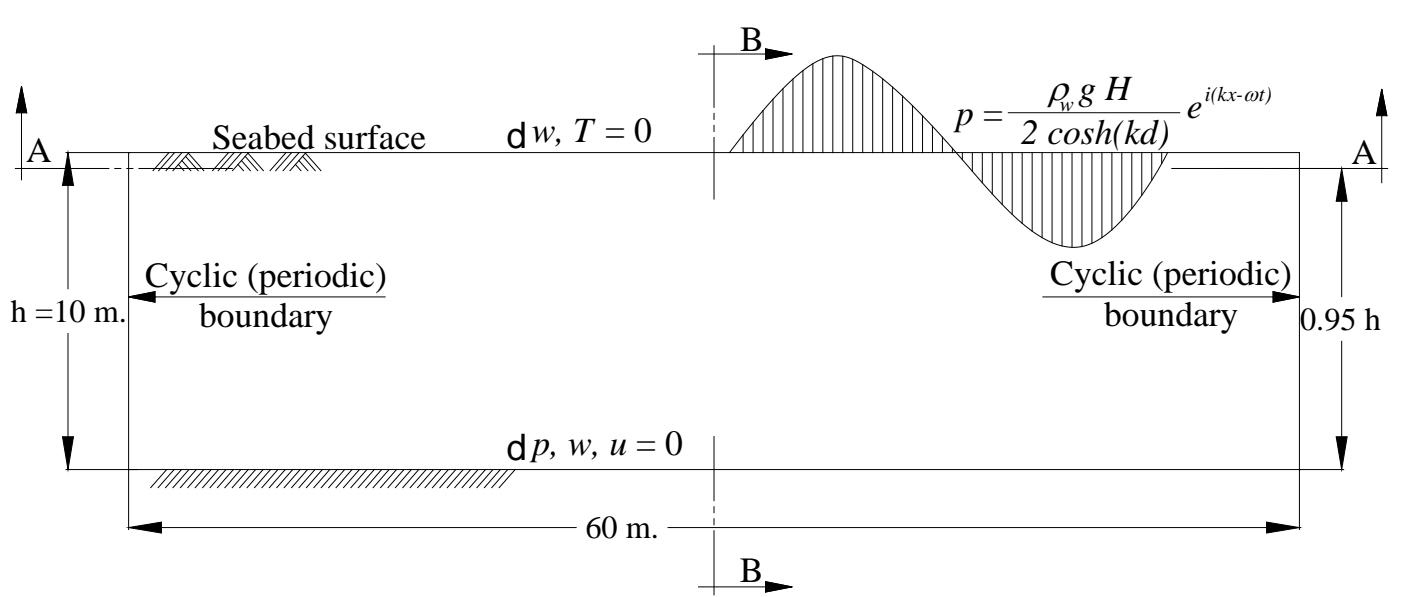

Figure 3. Computational domain of the seabed subject to wave action (see results of corresponding sections A-A in Fig. 4 and section B-B in Fig. 5)

Table 3. Wave loading conditions

Wave height $(H)$

Wave length $(L)$

Wave period $(T)$

Water depth $\left(d_{w}\right)$

Wave steepness. (H/L)

Ratio of water depth to wave length $\left(d_{w} / L\right)$
$1 \mathrm{~m}$.

$34.907 \mathrm{~m}$.

$5 \mathrm{~s}$.

$8 \mathrm{~m}$.

0.0286

0.2292 


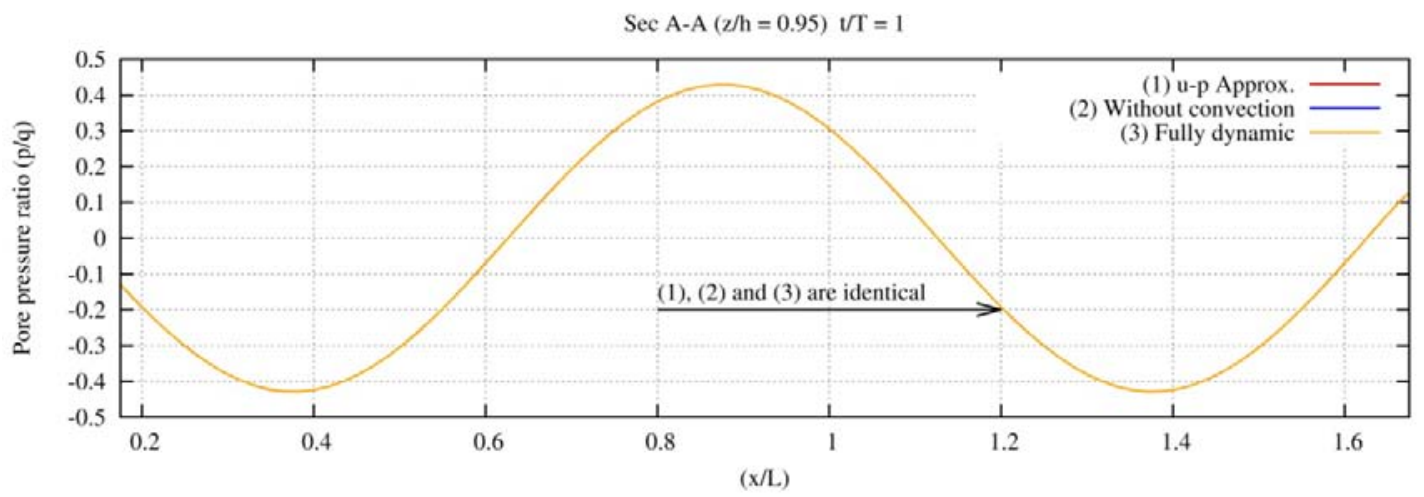

Figure 4. Pore pressure inside the seabed foundation (section A-A)
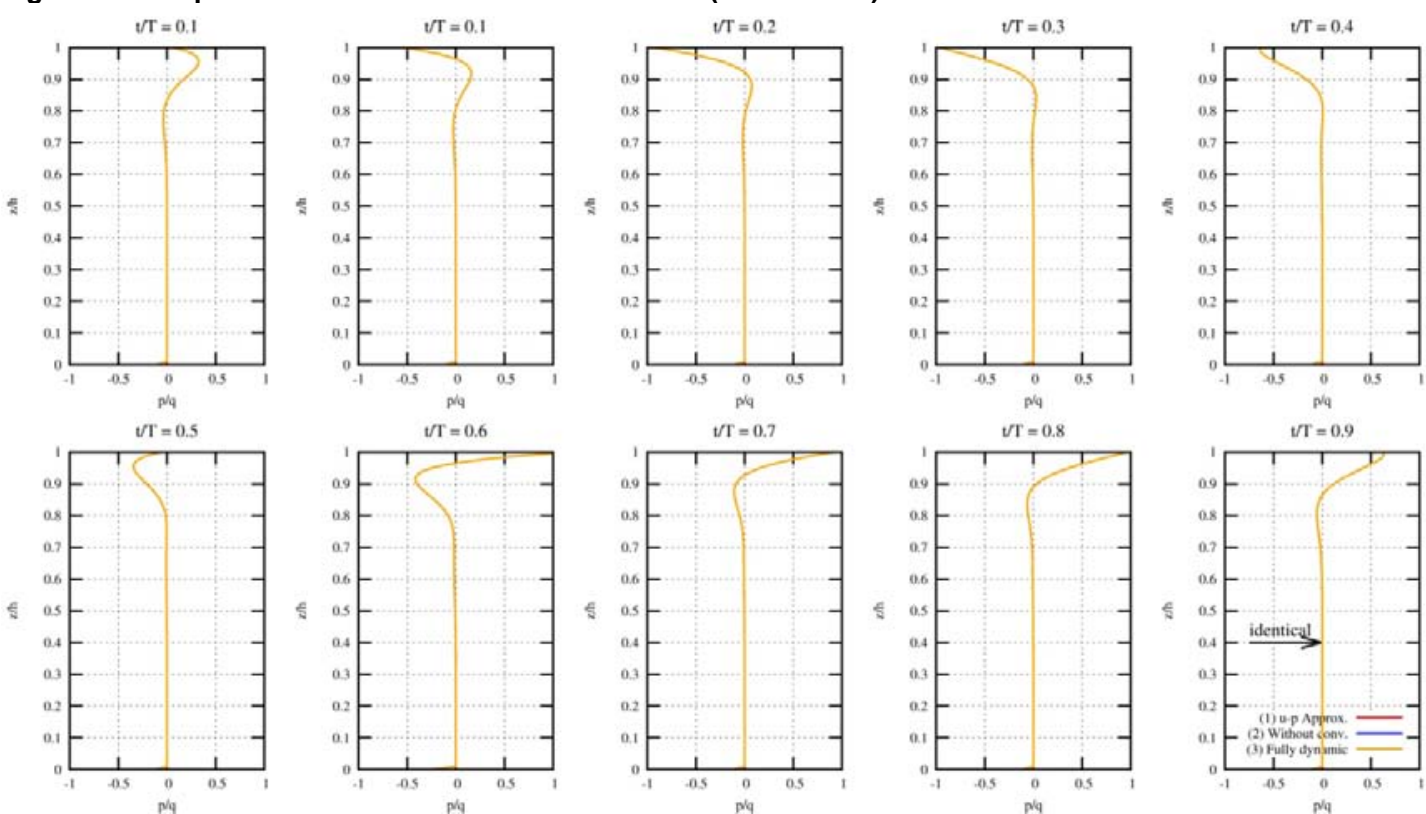

Figure 5. Pore pressure ratio to wave pressure amplitude (section B-B)

\section{SOIL-STRUCTURE INTERACTION}

Several strategies are available for modelling soil-structure interaction. These methods include the introduction of special springs or special elements at the interface. These simplifications are acceptable for small and continuous relative displacements of the interface. Nevertheless, the introduction of realistic contact constraints (boundary conditions) is essential for highly dynamic conditions.

For the structure-soil interface, a contact model was implemented which can simulate the separation and reattachment of soil and structure adjacent surfaces. The contact also accounts for friction between caisson surface and sand foundation. The non-linearity of the system is caused by the fact that the boundary condition is solution-dependant. The contact interface is updated via a penalty method algorithm.

A mixed boundary condition (Dirichlet-Neuman) is defined for the displacement at the contact boundary. A fixed value (Dirichlet) is used for displacement component normal to contact surface while a fixed displacement gradient (Neumann) is used for tangential components (friction). This mixed boundary condition is defined for the surface normal. Three values are defined: (i) the displacement, (ii) the displacement gradient and (iii) the value-fraction to define which part of the boundary is in contact and consequently which fraction of the displacement value and gradient is assigned for the calculation.

Different (potential) pairs of contact surfaces are defined by the user and one of them is assigned a mixed boundary condition and the other is assigned a fixed-gradient boundary condition. Both boundaries are updated together when the contact surfaces overlap (during iterations).

A generalized procedure is used to find the overlapping parts of the contact surfaces according to Jasak and Weller $\left(2000^{\mathrm{b}}\right)$. The normal contact constraint can be represented as (Sheng et al., 2007): 


$$
g_{n}=0 \text {, when } \sigma_{n}^{\prime}>0 ; g_{n}>0 \text {, when } \sigma_{n}^{\prime}=0 ; g_{n} \sigma_{n}^{\prime}=0
$$

Where $g_{n}$ is the relative displacement in normal direction (separation) and $\sigma_{n}$ is the normal stress component. The contact adopts Coulomb's law of friction for tangential constrains (Sheng et al., 2007), as:

$$
\begin{gathered}
g_{t}=0 \text {, when } \mu \sigma_{n}^{\prime}-\left|\sigma_{t}\right|>0 ;\left|g_{t}\right|>0 \text {, when } \mu \sigma_{n}^{\prime}-\left|\sigma_{t}\right|=0 ; \\
g_{t}\left(\mu \sigma_{n}^{\prime}-\left|\sigma_{t}\right|\right)=0
\end{gathered}
$$

Where $g_{t}$ is the relative displacement in tangential direction (slide). The tangential stress at contact is $\sigma_{t}$ and the coefficient of friction is $\mu$. No adhesion is simulated by the contact.

\section{SOIL CONSTITUTIVE MODEL}

Modelling the soil foundation as a continuum dictates the introduction of a material constitutive model for the solid phase of soil (i.e. the skeleton). Implementing simple material models (e.g. linear elasticity) in a fully coupled and fully dynamic poro-mechanical model can only reproduce the transient pore pressure in the soil. To model residual pore-pressure accumulation underneath monolithic breakwaters, the residual deformation of soil must be accounted for. Classical elasto-plastic models (where an elastic region of soil behaviour is enclosed by a plastic yielding envelope) are capable of reproducing soil behaviour when subject to monotonic loading. Nevertheless, in case of cyclic loads (especially with small amplitudes) classic elasto-plastic models tend to behave like elastic models (with load fluctuations occurring inside the elasticity region). Therefore, more sophisticated material constitutive models are needed to capture plasticity due to small changes in load-time history.

Unfortunately, no soil constitutive model exists, yet, that can be considered as standard for soil dynamic analysis. Nevertheless, several promising models exist with advantages and disadvantages in reproducing behaviour of soil under specific conditions. Densification models decouple the soil strain into monotonic part and a densification part (damage) caused by cyclic loading. Densification models are relatively simple but may suffer on the accuracy side. Multi-yield surface (kinematic) models approximate the stress-strain curve for soil into small linear segments (e.g. Elgamal et al., 2003). Bounding surface models use only two surfaces from which the inner surface can translate inside the outside "failure" surface eliminating the need for other yield surfaces and reducing calculation time. Some other models need no explicit definition of a yield (failure) surface like the generalized plasticity models (e.g. Jeng and Ou, 2010; Stickle et al., 2012) and hypoplastic models.

An interface for material models implementation in the geotechFoam solver has been developed. Different material models can be considered simultaneously for different regions of the domain. A multi-surface plasticity model (Prévost, 1985; Elgamal et al., 2003; Yang et al., 2003) has been implemented in the geotechFoam solver. The model uses an incremental stress-strain relationship so Hooke's law applies. The strain is conveniently decomposed into elastic and plastic components and the stress-strain relationship is:

$$
d \boldsymbol{\sigma}^{\prime}=\mathbf{E}:\left(d \boldsymbol{\varepsilon}-d \boldsymbol{\varepsilon}^{p}\right)
$$

Where $d \boldsymbol{\sigma}$ is the effective stress rate tensor, $\mathbf{E}$ is the fourth order elasticity tensor, $d \boldsymbol{\varepsilon}$ is the strain rate tensor and $d \boldsymbol{\varepsilon}^{\mathbf{p}}$ is the plastic strain rate tensor. Anisotropy is considered to be due to plasticity; therefore, any elastic anisotropy is omitted. Consequently, the former relation is simplified to:

$$
d \boldsymbol{\sigma}^{\prime}=2 G\left(d \boldsymbol{\varepsilon}-d \boldsymbol{\varepsilon}^{p}\right)+\left(K-\frac{2 G}{3}\right)\left(\operatorname{tr}(d \boldsymbol{\varepsilon})-\operatorname{tr}\left(d \boldsymbol{\varepsilon}^{p}\right)\right) \mathbf{I}
$$

Nonlinear elasticity can be introduced by considering elastic parameters to be functions of confinement (Prévost, 1985):

$$
G=G_{r}\left(\frac{p^{\prime}+p_{0}^{\prime}}{p^{r}+p_{0}^{\prime}}\right)^{a} \quad \text { and } \quad K=K_{r}\left(\frac{p^{\prime}+p_{0}^{\prime}}{p^{r}+p_{0}^{\prime}}\right)^{a}
$$


Where $\left(G_{r}\right)$ and $\left(K_{r}\right)$ are the reference shear modulus and reference bulk modulus, which correspond to the reference effective mean normal stress $\left(p^{r}\right), p^{\prime}=\operatorname{tr}(\boldsymbol{\sigma}) / 3$ is the mean effective stress and a small positive constant $\left(p_{0}^{\prime}\right)$ is considered for numerical convenience. The parameter $a$ equals 0.5 for most cohesionless soils. The plastic strain is calculated as:

$$
d \mathbf{\varepsilon}^{p}=\mathbf{P}\langle L\rangle
$$

$\mathbf{P}$ is a symmetric second-order tensor which defines the direction of plastic deformation in stress space. The \langle\rangle are MacCauley's brackets, so $L$ (the plastic loading function) is set to zero if it has a negative value. $L$ is calculated as:

$$
L=\frac{1}{H^{\prime}}\left(\mathbf{Q}: d \boldsymbol{\sigma}^{\prime}\right)
$$

$H^{\prime}$ is the plastic modulus and $\mathbf{Q}$ is a symmetric second-order tensor that denotes the outer normal to yield surfaces. $\mathbf{P}$ and $\mathbf{Q}$ are decomposed into deviatoric $\left(\mathbf{P}^{\prime}\right.$ and $\mathbf{Q}^{\prime}$ ) and volumetric ( $P^{\prime \prime}$ and $Q^{\prime \prime}$ ) parts, as:

$$
\begin{aligned}
P^{\prime \prime} & =\operatorname{tr}(\mathbf{P}) / 3 \quad \text { and } \quad \mathbf{P}^{\prime}=\mathbf{P}-P^{\prime \prime} \mathbf{I} \\
Q^{\prime \prime} & =\operatorname{tr}(\mathbf{Q}) / 3 \quad \text { and } \quad \mathbf{Q}^{\prime}=\mathbf{Q}-Q^{\prime \prime} \mathbf{I}
\end{aligned}
$$

The $Q$ tensor is normalized as:

$$
\mathbf{Q}=\frac{\partial f_{m} / \partial \boldsymbol{\sigma}^{\prime}}{\left\|\partial f_{m} / \partial \boldsymbol{\sigma}^{\prime}\right\|}
$$

Where $\left(f_{m}\right)$ is the yield function of the $\mathrm{m}^{\text {th }}$ surface, and $\partial f_{m} / \partial \boldsymbol{\sigma}^{\prime}$ is its gradient in the stress space. The model employs the pressure dependent Drucker-Prager yield criterion (Prévost, 1985; Elgamal et al., 2003; Yang et al., 2003):

$$
f_{m}=3 / 2\left(\mathbf{s}-\left(p^{\prime}+p_{0}^{\prime}\right) \boldsymbol{\alpha}^{m}\right):\left(\mathbf{s}-\left(p^{\prime}+p_{0}^{\prime}\right) \alpha^{m}\right)-M_{m}^{2}\left(p^{\prime}+p_{0}^{\prime}\right)^{2}
$$

For which:

$$
\frac{\partial f_{m}}{\partial \boldsymbol{\sigma}}=3\left(\mathbf{s}-\left(p^{\prime}+p_{0}^{\prime}\right) \boldsymbol{\alpha}^{m}\right)+\left(\left(p^{\prime}+p_{0}^{\prime}\right)\left(\boldsymbol{\alpha}^{m}: \boldsymbol{\alpha}^{m}-2 / 3 M_{m}^{2}\right)-\mathbf{s} \boldsymbol{\alpha}^{m}\right) \mathbf{I}
$$

The deviatoric stress tensor $\mathbf{s}$ is calculated as $\mathbf{s}=\boldsymbol{\sigma}^{\prime}-\left(p^{\prime}\right) \mathbf{I}$. The kinematic deviatoric tensor $\boldsymbol{a}^{m}$ defines coordinates of the $\mathrm{m}^{\text {th }}$ yield surface's centre in stress subspace (stress deviatoric plane/view) and $M_{m}$ is a scalar that defines the $\mathrm{m}^{\text {th }}$ surface size and, therefore, is a material parameter for the most outer surface (failure surface) and obtained for inner surfaces from piecewise linearization of the octahedral shear stress-strain curve (triaxial-stress plane) retrieved from lab experiments or soil's backbone curve (Fig. 6).

The flow rule determines how the outer normal to the plastic potential function (P) is calculated. Generally, a non-associative flow rule is considered for cohesionless soils to better model shearvolumetric strain interaction. In this model, the deviatoric part of the flow rule is associative $\left(\mathbf{P}^{\prime}=\mathbf{Q}^{\prime}\right)$ while the volumetric part $\left(P^{\prime \prime} \neq Q^{\prime \prime}\right)$ is non-associative (consequently the flow rule as a whole is nonassociative; $\mathbf{P} \neq \mathbf{Q}$ ). According to the stress state position (in the effective principal stress space) relative to the phase-transformation surface (defined by soil properties) three formulae are used to calculate $P^{\prime \prime}$. If the soil is in the contractive phase, $P^{\prime \prime}$ is calculated by (Yang et al., 2003):

$$
P^{\prime \prime}=\left(1-\operatorname{sign}(d \eta) \frac{\eta}{\eta_{P T}}\right)\left(c_{1}+c_{2} \varepsilon_{c}\right)\left(\frac{p^{\prime}}{p_{a t m}}\right)^{c 3}
$$




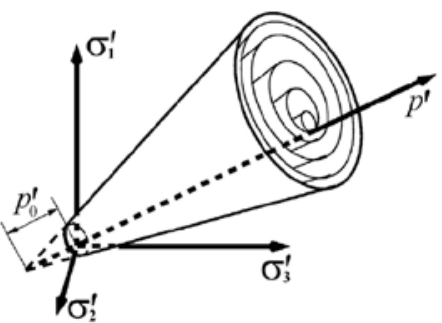

(a)

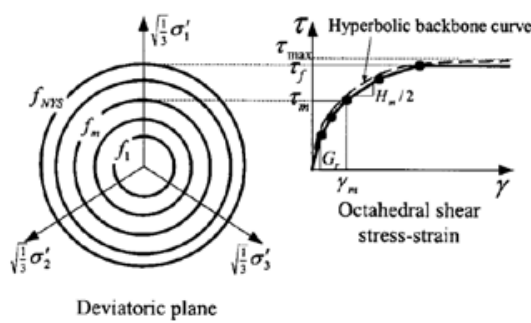

(b)

Figure 6. (a) Conical yield surfaces in principal stress space and (b) Hyperbolic backbone curve for soil nonlinear shear stress-strain response and piecewise-linear representation in multi-surface plasticity (after Prevost 1985 and Yang et al., 2003)

If the soil is in the dilative phase, $P^{\prime \prime}$ is calculated as (Yang et al., 2003):

$$
P^{\prime \prime}=\left(1-\frac{\eta}{\eta_{P T}}\right) d_{1}\left(\gamma_{d}\right)^{d_{2}}\left(\frac{p^{\prime}}{p_{a t m}}\right)^{d 3}
$$

; Where $\mathrm{c}_{1-3}$ and $\mathrm{d}_{1-3}$ are material parameters.

If the stress state lays on the phase transformation surface, is considered zero. The hardening rule is a pure deviatoric kinematic one. Consequently, all surfaces do not change size. They do, however, translate except for the outermost surface which is considered as a failure surface (the stress state cannot lay outside it). The direction of translation is selected independently of any formal plasticity constraints to ensure no overlapping between yield surfaces (Elgamal et al., 2003; Prevost, 1985; Mroz, 1967). To translate the active surface $\left(f_{m}\right)$ so that the new (deviatoric) stress state (s) lies on its new position, a conjugate stress state $\left(\mathbf{s}^{\mathbf{T}}\right)$ that lies on the outer yield surface $\left(f_{m+1}\right)$ and thus satisfies its yield function (Fig. 7) is defined as:

$$
\mathbf{s}^{T}=x\left(\mathbf{s}-p^{\prime} \boldsymbol{\alpha}^{m}\right)+p^{\prime} \boldsymbol{\alpha}^{m}
$$

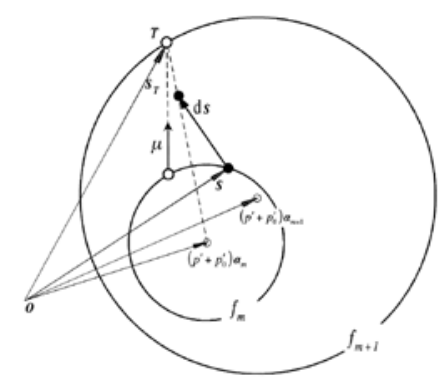

Figure 7. Deviatoric hardening rule (after Parra, 1996)

The unknown is $(x)$. Solving for $(x)$ yields a quadratic equation (Drucker-Prager criterion). The direction of the surface translation is given as (Parra, 1996):

$$
\boldsymbol{\mu}=\left(\mathbf{s}^{T}-p^{\prime} \boldsymbol{\alpha}^{m}\right)-\frac{M_{m}}{M_{m+1}}\left(\mathbf{s}^{T}-p^{\prime} \boldsymbol{\alpha}^{m+1}\right)
$$

The implemented constitutive model has been calibrated and validated for medium sand in several publications (e.g. Elgamal et al., 2003; Yang et al., 2003). It has shown to reproduce, adequately, sand behaviour under cyclic loading.

\section{LARGE-SCALE PHYSICAL EXPERIMENTS}

Large-scale physical experiments of a caisson breakwater resting on a sandy foundation were carried out in the large wave flume (GWK) in the Coastal Research Centre (FZK) in Hanover. The flume is about $330 \mathrm{~m}$ long, $5 \mathrm{~m}$ wide and $7 \mathrm{~m}$ deep. The wave paddle is driven by a $900 \mathrm{~kW}$ maximum power engine. After a horizontal bottom of $250 \mathrm{~m}$. the flume is limited by an impermeable embankment with a slope of 1:6. 


\section{Experimental Set-Up}

The investigated model construction includes the sand body beneath the breakwater, the rubble foundation with a seaward berm and the caisson breakwater. The configurations of the flume and wave gauges are shown in Fig. 8 (Oumeraci and Kudella, 2004; Kudella et al., 2006). The sand profile consists of a beach profile with a 1:25 slope, starting at $\mathrm{x}=169.6 \mathrm{~m}$ and ending at $\mathrm{x}=230.5 \mathrm{~m}$ with a height of $2.45 \mathrm{~m}$ above the flume bottom. The profile continues horizontally up to the (1:6) embankment.

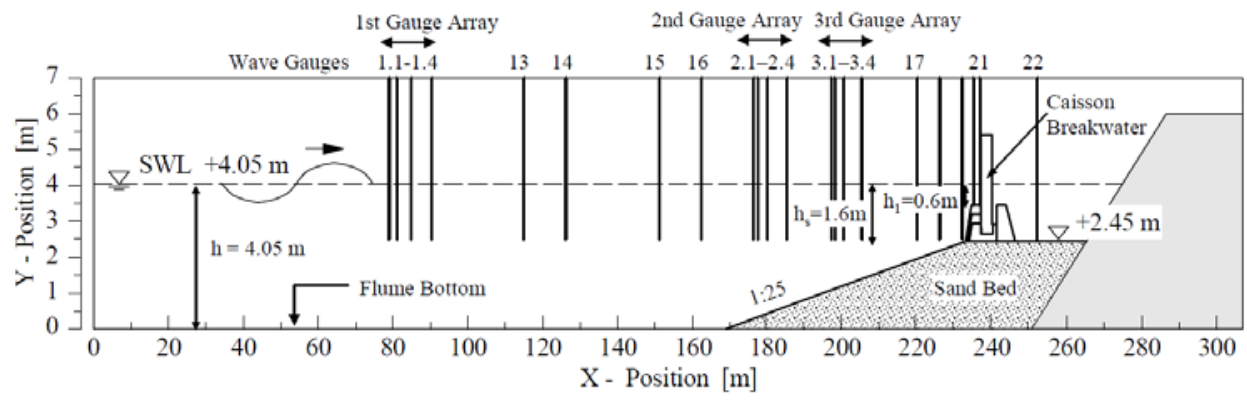

Figure 8. Caisson breakwater model with locations of wave gauges in the Large Wave Flume (Oumeraci and Kudella, 2004)

The sand foundation was placed with a special procedure to reduce the initial air content. The test programme was composed of two phases. The first phase was focused on the direct loading of soil foundation by smaller water waves without the existence of any structure in order to compact the loose sand (due to installation procedure). The second phase was carried out after the construction of the caisson breakwater. The largest part of the profile consists of a medium sand with a grain size of $\mathrm{D}_{50}=$ $0.35 \mathrm{~mm}$. However, underneath the breakwater model finer sand with $\mathrm{D}_{50}=0.21 \mathrm{~mm}$ was chosen. The finer sand was separated from the rest of the sand profile by two walls made of geotextile bags filled with sand. In addition the part with the finer sand was separated from the adjacent sand profile by an impermeable PE-sheet on the bottom and at the sides to prevent drainage and thus the dissipation of the expected excess pore pressure generated during the tests.

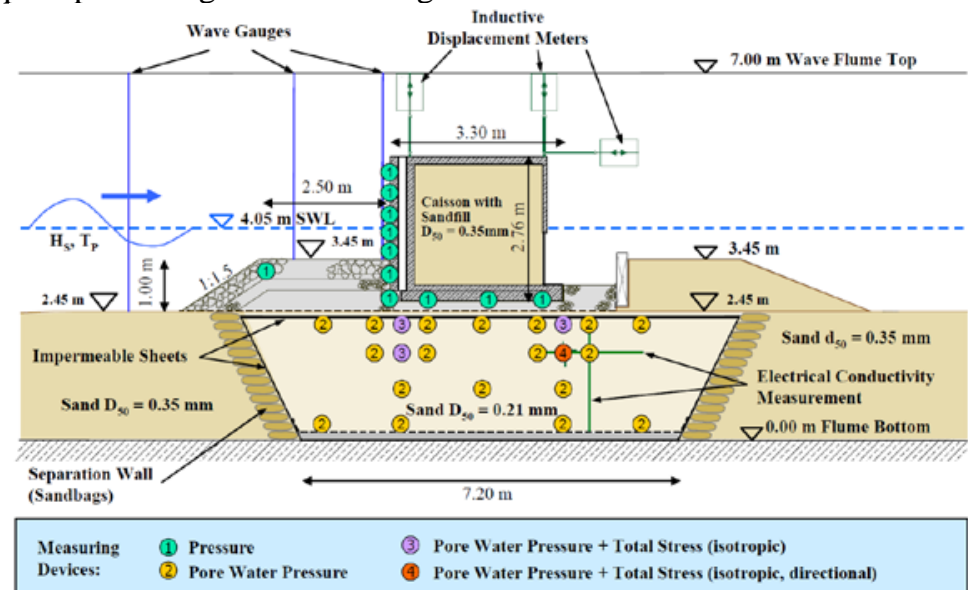

Figure 9. Cross section of the model with locations of measuring devices (Oumeraci and Kudella, 2004)

The locations of the deployed measurement devices are shown in Fig. 9. The pore pressure transducers are positioned on a wooden frame that is buried inside the sand foundation. The response of the caisson due to wave load was recorded directly by 3 displacement meters. Due to the expected large residual motions, the measuring system was planned to measure simultaneously the small vibrations of the caisson as well as the larger residual settlements and horizontal sliding. Each gauge measured the elongation at the structure top ( 2 vertical \& 1 horizontal). Based on the measurements of the three devices the different types of motions of the caisson were calculated.

\section{Numerical Simulations}

The idealization for the geometry of the experiments for numerical simulations with the geotechFoam solver is shown in Fig. 10. The contact surfaces are defined between the caisson and the 
rubble foundation as well as between the shutter beam and surrounding sand/rubble. The impermeable PE-Sheet is approximated as a volume of arbitrary thickness and given an equivalent modulus of elasticity based on its original thickness. Two gaps of arbitrary height are defined in the PE-sheet to allow seepage of pore fluid as the PE-Sheets are separated at these locations. The geotextile sand bags are averaged as a sand continuum with a slight increase in material elasticity modulus and angle of internal friction to account for the bags confinement effect for walls on both sides of the PE-sheet.

For the purpose of preliminary testing of the solver, the displacements at the top of the caisson (retrieved from measurements) are imposed to the caisson breakwater instead of directly introducing the hydrodynamic loads (wave pressure transferred directly to the soil foundation beneath the caisson are not considered). This is justified by the observation that pore pressure build-up in sand foundations underneath caisson breakwaters is substantially due to caisson motion (Kudella et al., 2006). The displacements at the top of the structure (points B and C in Fig. 10) are calculated from the recorded elongations of the displacement meters at top of caisson (Fig. 9). The characteristics of the boundary conditions (as illustrated in Fig. 10) are presented in Table 4.

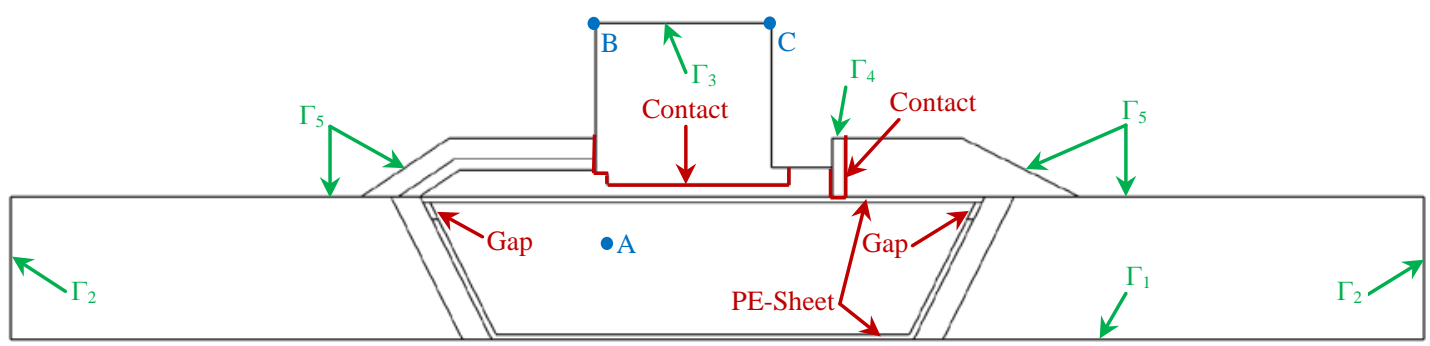

Figure 10: Idealized geometry for the caisson breakwater and its foundation as tested in GWK

Table 4. Boundary Conditions

\begin{tabular}{|l|l|l|l|l|}
\hline & Description & $\mathbf{u}$ & $\boldsymbol{p}$ & $\mathbf{w}$ \\
\hline$\Gamma_{1}$ & Bottom of geometry & $u=0$ - "Fixed bottom" & $\nabla p=0$ & $\mathbf{w}=0$ \\
\hline$\Gamma_{2}$ & Sides of geometry & Mixed - "Allows vertical settlement" & $\nabla p=0$ & $\nabla \mathbf{w}=0$ \\
\hline$\Gamma_{3}$ & Caisson top (input of experimental disp.) & Value - “Experiments" & Value & $\nabla \mathbf{w}=0$ \\
\hline$\Gamma_{4}$ & Top and left side of shutter beam & $u=0$ & Value & $\nabla \mathbf{W}=0$ \\
\hline$\Gamma_{5}$ & Other outer boundaries (e.g. rubble surface) & $\nabla u=0$ & Value & $\nabla \mathbf{W}=0$ \\
\hline
\end{tabular}

By introducing a sudden displacement at the caisson top followed by random oscillations, the solver results indicate its ability to reproduce accumulation and further dissipation of pore pressure. This is shown for point A in Fig. 11. Considering one of the tests from the large-scale caisson breakwater experiments, the pore pressure at point " $\mathrm{A}$ " retrieved from numerical simulations is comparable to experimental measurements (Fig. 12). The results are promising and it is expected that further adjustments of the model parameters and configurations of the simulation will enhance the model results. The figure also shows a difference in results when the pore fluid acceleration is considered.

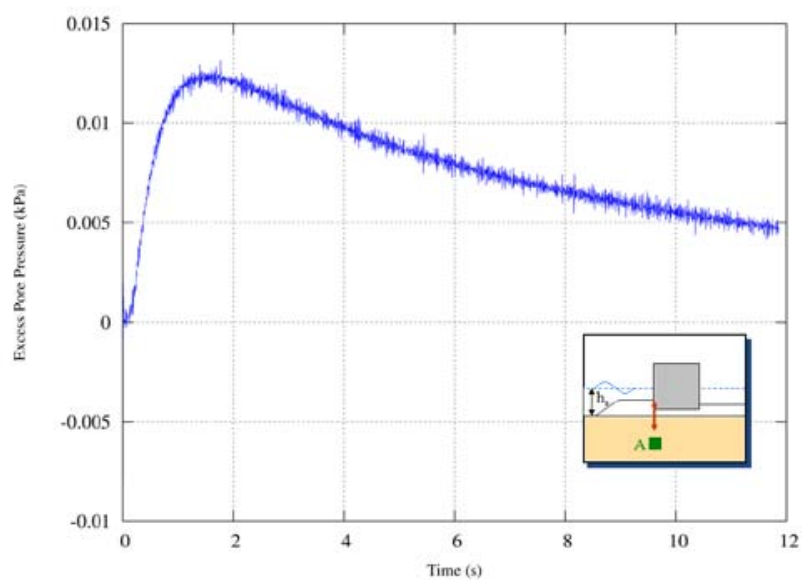

Figure 11: Computed (build-up) and dissipation of residual pore pressure underneath caisson breakwater's seaside edge (point $A$ ). 


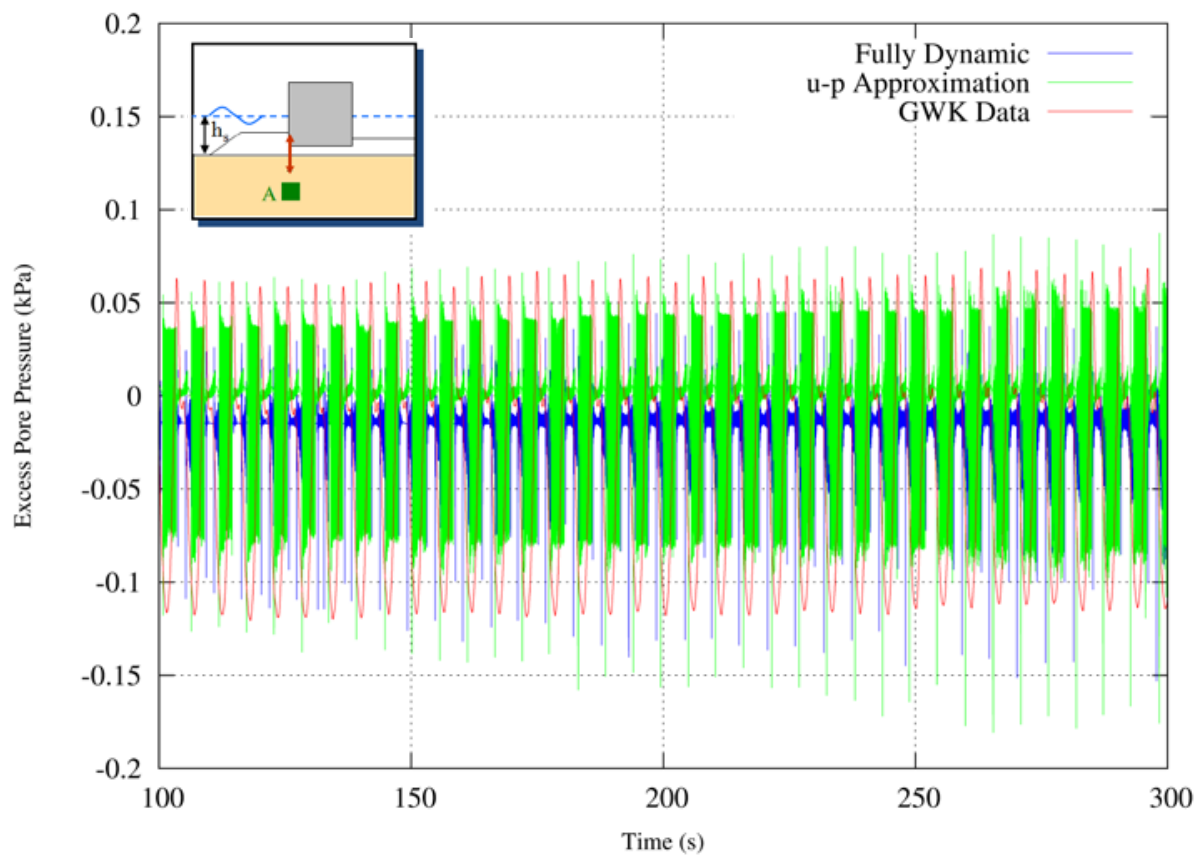

Figure 12: Comparison of measured pore pressure (point $A$ ) and numerically retrieved values for fully and partially dynamic formulations $(H=0.4 \mathrm{~m} . \& \mathrm{~T}=5.5 \mathrm{~s}$. $)$.

\section{WORK IN PROGRESS AND OUTLOOK}

Adjustments of the configurations and parameters to enhance comparison of the solver results to the large-scale model data from the GWK tests will be presented in a forthcoming paper. The solver will be coupled with a CFD solver to provide an integrated tool for the numerical analysis of the loading and response of caisson breakwater foundations. The coupled CFD-CSD will be applied to perform a more systematic parameter study which will extend the conditions tested in GWK, thus allowing us to develop more simple formulae for the prediction of the foundation response to the structure motions induced by breaking and non-breaking wave loads. Further, the use of the PISO algorithm to resolve pore fluid pressure-velocity coupling will allow us to introduce a closer coupling (equation level) for CSD-CFD solvers.

\section{SUMMARY AND CONCLUDING REMARKS}

A new finite volume model is introduced to model seabed as porous media using Biot's fully dynamic formulation using a segregated algorithm. It is found that neglecting the pore fluid convective acceleration increases time needed for conversion and hence not favoured. As expected, the model is very sensitive to air content in pore fluid (introduced to the fluid phase bulk modulus).

The fluid momentum balance is solved in the PISO based approach instead of being considered implicitly in the mass conservation equation in other approaches. Hence, the PISO based model calculates the total pore pressure instead of calculating the excess pore pressure in other approximations. It is further observed that for the fully dynamic model the generation/dissipation of excess pore pressure is affected by the ratio of the excess pore pressure to the hydrostatic pore pressure.

Seabed response to direct wave action is identical for all formulations implying indifference to dynamic terms (in absence of any structure). Difference between the fully dynamic and the $u-p$ formulation is observed for the dynamic response of seabed underneath the caisson breakwater and will be further studied with emphasis on caissons subject to breaking wave impact.

Different material models can be explicitly introduced to the model. A multi-surface plasticity model is implemented to reproduce the behaviour of sand foundation under cyclic loading imposed by caisson motions. The use of the elastic-plastic model enables the simulation of pore pressure accumulation (build-up) and dissipation. Further, a frictional contact model is implemented in the solver to simulate soil-structure interaction. Preliminary validation with large-scale experiments from the GWK shows promising results. 


\section{ACKNOWLEDGMENT}

Financial support of both the Egyptian government and the German Academic Exchange Service (DAAD) within the German Egyptian Research Long-term Scholarship (GERLS) programme, for the first author doctoral studies, is gratefully acknowledged.

\section{REFERENCES}

Detournay, E. and Cheng, A.H.-D. 1993. Fundamentals of Poroelasticity, Chapter 5 in Comprehensive Rock Engineering: Principles, Practice and Projects, Vol. II, Analysis and Design Method, ed. C. Fairhurst, Pergamon Press, pp. 113-171.

El Safti, H. and Oumeraci, H. 2012. Wave-structure-foundation interaction: structural model, Internal Report, Leichtweiß-Institute for Hydraulic Engineering and Water Resources, TU-Braunschweig, Germany.

Elgamal, A., Yang, Z., Parra, E., and Ragheb, A. 2003. Modeling of Cyclic Mobility in Saturated Cohesionless Soils, International Journal of Plasticity, Pergamon, Elsevier Science Ltd., Vol. 19, Issue 6, pp. 883-905.

Jasak, H. 1996. Error analysis and estimation for the Finite Volume method with applications to fluid flows, PhD. Thesis, Imperial College, University of London.

Jasak, H. and Weller, H.G. 2000 ${ }^{\mathrm{a}}$. Application of the Finite Volume Method and Unstructured Meshes to Linear Elasticity, Int. J. Num. Meth. Engineering 2000, v 48, n 2, pp 267-287

Jasak, H. and Weller, H.G. 2000 ${ }^{\mathrm{b}}$. Finite volume methodology for contact problems of linear elastic solids, Proceedings of $3^{\text {rd }}$ International Conference of Croatian Society of Mechanics, Cavtat/Dubrovnik, September 2000.

Jeng, D.-S. 2003. Wave-induced sea floor dynamics. Applied Mechanics Reviews, ASME, 56(4), 407429, pp.

Jeng, D.-S., and Ou, J. 2010. 3D models for wave-induced pore pressures near breakwater heads. Acta Mechanica. doi: 10.1007/s00707-010-0303-z.

Kudella, M., Oumeraci, H., de Groot, M.B. and Meijers, P. 2006. Large-Scale Experiments on Pore Pressure Generation underneath a Caisson Breakwater. Journal of Waterway, Port, Coastal, and Ocean Engineering, Vol. 132, No. 4, pp. 310-324.

Liu, X. and García, M.H. 2006. Numerical Simulation of sea bed response under waves with coupled solver of Biot consolidation equations and free surface water flow. In proceeding of ISOPE PACOMS, Dalian, China.

Mroz, Z. 1967. On the description of anisotropic work hardening. J. Mech. Phys. Solids, 15, 163-175.

Oumeraci, H. 1994. Review and Analysis of Vertical Breakwater Failures - Lessons learned. Coastal Engineering, Special Issue on "Vertical Breakwaters", Amsterdam, The Netherlands: Elsevier Science Publishers B.V., vol. 22, nos. 1/2, pp 3- 29.

Oumeraci, H. 2004. Breakwaters, Part 2. In: Agerschou, H. (ed.): Planning and design of ports and marine terminals, London, U.K.: Thomas Telford, pp. 155-262.

Oumeraci, H., Kortenhaus, A. 1994. Analysis of Dynamic Response of Caisson Breakwaters. Coastal Engineering, Special Issue on "Vertical Breakwaters", Oumeraci, H. et al., Amsterdam, The Netherlands: Elsevier Science Publishers B.V., vol. 22, nos. 1/2, pp. 159-183.

Oumeraci, H., Kortenhaus, A., Allsop, N.W.H., De Groot, M.B., Crouch, R.S., Vrijling, J.K., Voortman, H.G. 2001. Probabilistic design tools for vertical breakwaters. Rotterdam, The Netherlands: Balkema, 392 pp.

Oumeraci, H., Kudella, M. 2004. Liquefaction around marine structures (LIMAS) - Work package 3, large scale experiments on a caisson breakwater. Technical report of Leichtweiß-Institute for Hydraulic Engineering and Water Resources, Technical University Braunschweig, Braunschweig, Germany, 119 pp.

Prévost, J. H. 1985. A simple plasticity theory for frictional cohesionless soils. Soil Dyn. Earthquake Eng., 4(1), 9-17.

Sheng, D., Wriggers, P., Sloan, S. W. 2007. Application of Frictional Contact in Geotechnical Engineering. International journal of geomechanics. ASCE / May/June 2007.

Stickle, M.M., Pastor, M. and Dutto, P. 2012. Mathematical and Numerical Modeling in Maritime Geomechanics. Pensamiento Matemático ISSN-e 2174-0410, №. 2 (April), 2012, 21 pp.

Ülker, M.B.C., Rahman, M.S., and Guddati, M.N. 2012. Breaking wave-induced response and instability of seabed around caisson breakwater. Int. J. Numer. Anal. Meth. Geomech. 2012; 36:362-390. 
Verruijt, A. 2001. Soil Mechanics, TU Delft OCW: Available at: ocw.tudelft.nl

Yang, Z., Elgamal, A., and Parra, E. 2003. Computational Model for Cyclic Mobility and Associated Shear Deformation, J. Geotechnical and Geoenvironmental Engineering, ASCE, Vol. 129, Nr. 12, pp. 1119-1127

Yang, Z., Lu, J. and Elgamal, A. 2008. OpenSees Soil Models and Solid-Fluid Fully Coupled Elements. User's Manual. Ver 1.0. University of California, San Diego, 25 pp.

Zienkiewicz, O.C., Chan, A.H.C., Pastor, M., Schrefler, B.A. and Shiomi, T. 1999. Computational Geomechanics (with Special Reference to Earthquake Engineering). UK: John Wiley \& Sons Ltd, $383 \mathrm{pp}$.

Zienkiewicz, O.C. and Shiomi., T 1984. Dynamic Behaviour of Saturated Porous Media; The Generalized Biot Formulation And Its Numerical Solution. International, Journal for Numerical Methods in Engineering, 8:71-96. 